\title{
EXPLORING STUDENTS' INTERPRETATIONS OF SUCCESS: A RESEARCH INSTRUMENT
}

\author{
Max Ullrich and David S. Strong \\ Queen's University at Kingston, Ontario \\ Ullrich.Max@queensu.ca and David.Strong@queensu.ca
}

\begin{abstract}
The nebulous term 'student success', and other similar terms such as 'academic success', are widely used in education research papers as all-encompassing phrases representing a wide variety of student outcomes, typically academic achievement and persistence. There is limited research addressing how success during an undergraduate engineering program is defined from the student point of view. A 60-question research survey with 266 responses, a response rate of $8 \%$, was conducted at Queen's University to explore this gap. The survey was validated with a mixed-methods pilot study. Instrument validity, reliability, and fairness were established during the full study. Scale reliability for a modified version of a Future Time Perspectives survey was established using an exploratory factor analysis with a "meritorious" KMO of 0.81 with five factors explaining $49.60 \%$ of the variance.
\end{abstract}

Keywords: Student success, academic success, research instrument development, pilot study, reliability, exploratory factor analysis.

\section{INTRODUCTION}

The nebulous term 'student success', and other similar terms such as 'academic success', are widely used in education research (including Canadian Engineering Education research) as all-encompassing phrases representing a wide variety of student outcomes [1-3]. Typically, the actual outcomes represented by these terms are academic achievement (grades and GPA), and persistence (retention or graduation rates). However, grades are not necessarily an accurate measure of learning or cognitive growth $[4,5]$. Also, the term "success" can have different meanings for each stakeholder group in the academic environment, and can vary amongst members of a single stakeholder group [6]. For example, a professor could define student success by each student's level of understanding of the course material while a policymaker may see student success in terms of the 7-year graduation rate. More than one indicator is necessary to document a more accurate and nuanced picture of student success to represent different stakeholders. To determine reasonable institutional indicators of student success, a variety of stakeholder groups must be involved, including policymakers, administrators, faculty, staff, education researchers and perhaps most critically, students [7]. There is plenty of documentation from the point of view of institutions and education researchers, but there is limited research addressing the student point of view [8]. Therefore, a research study was conducted to begin to address this literature gap of how engineering students themselves define their success during their undergraduate program.

The purpose of the research study was to explore how undergraduate engineering students define success for themselves, investigate potential differences between different groups of students, and identify improvements students felt they could make to better reach their future career goals. A survey instrument was used to gather Likert and open-response data, and was validated with a two-part pilot study consisting of a survey pilot and think-aloud cognitive interviewing. The survey was then distributed to undergraduate engineering students at Queen's University.

This paper will discuss the survey instrument that was used in this study in terms of how it was developed, how it was assessed for integrity, and will also provide suggestions for future work. Ensuring integrity of the instrument is important to minimize potential bias and ensure that the survey actually measures what it sets out to measure. The purpose of this paper is to document the second iteration of the process used to plan, design, implement, test, and evaluate the survey instrument. The first iteration of this process was completed in the form of a pilot study and is discussed in more detail in a previous paper [9]. Documenting this process is useful both for researchers interesting in conducting research in this area and as a reference for anyone designing an engineering education survey.

\section{PREVIOUS WORK}

A convergent parallel mixed method pilot study was conducted to improve the survey before it was distributed to the full population. The purpose of the pilot study was to ensure consistent understanding of the survey questions to reduce measurement error and test for content coverage 
in order to assess and potentially increase reliability before running the full study [10-12]. The pilot study consisted of a survey pilot with 19 participants and think-aloud cognitive interviewing with 4 participants and is discussed in more detail in: [9].

Analysis of the survey pilot data was focused on descriptive statistics (response rate limited statistical power of other tests [13]) including skewness and kurtosis to assess the normality of data as well as a review of the maximum and minimum response values of each question to ensure the phrasing of the question did not dissuade certain answers.

Cognitive interviews were used to help understand how survey respondents answer survey questions by allowing a direct study of the question-and-answer process $[12,14]$. Two cognitive interviewing techniques were used: "thinking-aloud", and probing [12]. Think-aloud protocol involves the researcher asking the participant to "thinkaloud" as they review and answer each question in the survey, while probing involves the researcher asking the participant questions to encourage elaboration. These were used to identify potential sources of measurement error such as: (i) question comprehension issues; (ii) validity issues and discrepancies around question interpretation; and (iii) difficulties (or unwillingness) with cognitive process [11]. A 60-minute semi-structured interview was used to conduct the think-aloud and probing process.

The pilot study process identified three key areas for improvement: (i) imprecise wording of questions; (ii) biased phrasing (complete unwillingness to answer "disagree"); and (iii) questions lacking context. Overall, $25 \%$ of the survey questions were directly improved by this process and a remaining 50\% were indirectly improved by changing the prompts prefacing the survey section. This strongly supports the value of the time and effort invested in the pilot study.

\section{INSTRUMENT}

The full survey instrument received 266 responses and consisted of 57 closed-ended and 3 open-ended questions split into 7 sections. All Likert-style questions used a 7point "strongly disagree" to "strongly agree" scale to minimize confusion. The questions within each section were randomized to minimize survey bias (other than the demographics). The sections were: (i) demographics (8 items); (ii) defining your success during engineering program, framed around Beaty et al.'s Learning Orientation model [15] (17 items); (iii) open-ended response defining your success during engineering program; (iv) a selection of modified Future Time Perspectives questions [16] (21 items); (v) hypothetically defining your success during engineering program in such a way that it would best optimize future career success, framed around Beaty et al.'s Learning Orientation model [15] (9 items); (vi) open-ended response envisioning what success means in a future career; and (vii) connecting actual definition of success in current program to hypothetical "future-career-success-maximizing" definition of success (2 items) and an open-ended reflection. A few negatively worded questions were used to ensure respondents were reading each question and answering with some level of consistency.

The Learning Orientation Model [15] was used to frame ways in which students define their success and extract the relative "importance" of each of these ways. The Future Time Perspectives [16] model was used because it has been previously validated in an engineering education context and existing research suggested links between students with a high concern and consideration for the future (i.e. "higher" Future Time Perspective) to greater "success" in engineering programs [17-22].

\subsection{Validity}

Validity is a measure of how well a survey measures what it sets out to measure [23]. Face validity involves reviewing the appropriateness of the questions in a survey, as assessed by individuals without training in the area [23]. Face validity was established through the think-aloud interviews in the pilot study where non-experts verbalized their interpretations of the survey questions. Content validity involves reviewing the appropriateness of the questions in a survey, as assessed by those with training in the area [23]. This was established by utilizing a preexisting survey instrument that had already been validated in an engineering education context [16] during the development of the survey. Further, a two-step review was conducted by an engineering education research colleague, and then an engineering education research expert. Criterion validity and construct validity were not assessed because there is not yet a pre-existing "gold-standard" measure of the same variables to compare with, and there was not time during the study to collect years of experience with the instrument between numerous investigators [23].

\subsection{Reliability}

Reliability is a measure of how reproducible the results from a survey instrument are [23]. Reliability in terms of internal consistency, the measure of how well items in a scale vary together, was assessed using Cronbach's Alpha. Alternate-form reliability was not assessed for this instrument because it would have required distributing multiple versions of the survey, with questions reworded and targeting the same specific variable. Instead, the thinkaloud interview results were relied on to ensure consistent interpretations of the variables behind the questions. Furthermore, test-retest reliability was not assessed for this instrument because that was not the purpose of this study. This would have required a group of participants to complete the survey multiple times to check the stability of answers over time (and a student's answer to these types of questions have the potential to naturally change over time). 


\subsection{Fairness}

Instrument fairness identifies if, with an alternate survey or under different conditions, an individual or group may have fared better in responding to the survey [24]. Individual fairness (equity) was ensured because individuals could choose the location where they could respond to the online survey to suit their needs, there was no time limit, and the online format ensured students could use accessibility features of their phone or laptop to increase the text size or read text aloud, for example [24]. Group fairness was considered through an effort to make the survey questions as understandable to the widest range of respondents as possible by conducting think-aloud interviews with a variety of people. Also, questions related to gender included a 'self-identification' and a 'prefer not to answer' option.

\section{SCALE RELIABILITY}

The scale reliability of the Learning Orientation model survey questions was assessed using Cronbach's Alpha. The Learning Orientation Model has 8 sub-scales: vocational; academic; personal; and social - each with an intrinsic and extrinsic valence. Cronbach's Alpha values of 0.7 or above are widely considered acceptable, but values as low as 0.5 will suffice in the early stages of research [13, p. 602, 25]. When interpreting Cronbach's Alpha values, it must be noted that the value of Cronbach's Alpha increases with the number of items in the scale. Each of the 8 subscales shown in Table 1 only had 2 questions in it.

Table 1: Ways in which engineering students define their success during their undergraduate degree categorized using the Learning Orientation Model, with criteria shown in order from most important to least important and scale reliability shown.

\begin{tabular}{|l|l|l|c|}
\hline $\begin{array}{c}\text { Learning } \\
\text { Orientation }\end{array}$ & Interest & Mean & $\begin{array}{c}\text { Cronbach's } \\
\text { Alpha }\end{array}$ \\
\hline Vocational & Extrinsic & 6.25 & 0.79 \\
\hline Social & Extrinsic & 5.97 & 0.48 \\
\hline Vocational & Intrinsic & 5.97 & 0.63 \\
\hline Personal & Intrinsic & 5.92 & 0.65 \\
\hline Personal & Extrinsic & 5.84 & 0.28 \\
\hline Academic & Intrinsic & 5.75 & 0.43 \\
\hline Social & Intrinsic & 5.71 & 0.72 \\
\hline Academic & Extrinsic & 5.39 & 0.87 \\
\hline
\end{tabular}

This table shows that some of the subscales in this section appear unidimensional, and most subscales achieve a Cronbach's Alpha near or above 0.5. However, a subscale with Cronbach's Alpha as low as 0.28 and others in the 0.40 's cannot be ignored. Since Cronbach's Alpha suggested that certain subscales were not reliable, the survey questions in this section could not be condensed into those subscales and had to be analyzed individually.

\section{EXPLORATORY FACTOR ANALYSIS}

An exploratory factor analysis (EFA) was completed for the Future Time Perspective survey questions to identify clusters of variables that represent latent variables (factors). EFA was chosen because some of the questions in the original survey instrument [16] were modified and some additional questions were added. These changes needed to be confirmed with an EFA before a confirmatory factor analysis is completed. Three of the original six factors were utilized because these three factors investigate how the present and future are related, which is in line with the purpose of this study. The original instrument only investigated the extent to which students wanted to become a professional engineer in the future. As a result, this factor was renamed to "Perceptions of Engineering Future" and, a new factor and corresponding questions was added to reflect the fact that some engineering students may have a very good idea of what they want to do in the future, but they may not necessarily want to become a professional engineer. This factor was called "Perceptions of the Future" A final factor (Present Action) and corresponding questions was added that investigated whether or not students were actually presently taking action in regard to planning for their future. This differs from the Connectedness factor because Connectedness is about making a plan for the future and Present Action is about executing it.

EFA has three main uses, all of which were used for this survey: "(i) to understand the structure of a set of variables, (ii) to construct a questionnaire to measure an underlying variable, and (iii) to reduce a data set to a more manageable size while retailing as much of the original information as possible" [13, p. 571]. An EFA takes several measured variables and attempts to explain the highest amount of common variance using the lowest number of constructs. In other words, it takes the survey questions and tries to group them in such a way that tries to minimize the number of groups while maximizing the amount the survey questions within each group vary together.

Before the EFA, the correlation matrix was checked to see if any survey questions did not correlate well with any of the other questions (correlation less than 0.3), and as a result one question was removed (question Q4_19).

The Kaiser-Meyer-Olkin (KMO) measure of sampling adequacy was calculated to determine sample size adequacy. Generally, having more samples is considered better for an EFA. KMO values can be interpreted along the following guidelines: (i) marvelous for values in the $0.90 \mathrm{~s}$., (ii) meritorious for values in the $0.80 \mathrm{~s}$, (iii) middling for values in the $0.70 \mathrm{~s}$, (iv) mediocre for values in the $0.60 \mathrm{~s}$, (v) miserable for values on the 
$0.50 \mathrm{~s}$, and (vi) unacceptable for values below $0.5[13,26]$. The KMO for this analysis was 0.81 , meritorious.

Maximum likelihood factor extraction was used for this analysis, as recommended by Field (2018) for the ability to generalize from the sample to the population. Factor loadings with values over 0.4 were retained since that explains a minimum of $16 \%$ of the variance in the variable [27]. To determine the number of factors to retain, the factors with eigenvalues over one were retained with the result being verified by examining the turning point of the screen plot (as recommended by Field).

Initially, the oblique factor rotation Direct Oblimin was used to determine the magnitude of correlations between factors. Five factors had eigenvalues greater than 1 and explained a total of $48.75 \%$ of variance. One question did not load onto any of the factors, so it was also removed (question Q4_14). The correlation matrix for the oblique factor rotation is shown in Table 2.

Table 2: Correlation matrix for the oblique factor rotation.

\begin{tabular}{|l|c|c|c|c|c|}
\hline Factor & $\mathbf{1}$ & $\mathbf{2}$ & $\mathbf{3}$ & $\mathbf{4}$ & $\mathbf{5}$ \\
\hline $\mathbf{1}$ & 1 & & & & \\
\hline $\mathbf{2}$ & 0.19 & 1 & & & \\
\hline $\mathbf{3}$ & -0.37 & -0.29 & 1 & & \\
\hline $\mathbf{4}$ & -0.39 & 0.01 & 0.14 & 1 & \\
\hline $\mathbf{5}$ & -0.30 & -0.21 & 0.25 & 0.25 & 1 \\
\hline
\end{tabular}

The correlation between factors was small, all within $+/-0.4$, so the orthogonal rotation Varimax was used for the analysis as recommended by Field [13, p. 581, 28]. Orthogonal rotation is preferred, when possible, because the factors are easier to interpret because there is no correlation between factors [13]. The orthogonal rotation resulted in five factors explaining $49.60 \%$ of the variance. The results of the factor analysis can be seen below in Table 3 and the actual survey questions are shown in Table 5 in the appendix.

Table 3: Orthogonally rotated factor matrix.

\begin{tabular}{|l|c|c|c|c|c|}
\hline \multirow{2}{*}{$\begin{array}{c}\text { Survey } \\
\text { Question }\end{array}$} & \multicolumn{5}{|c|}{ Factor } \\
\cline { 2 - 6 } & F1 & F2 & F3 & F4 & F5 \\
\hline Q4_1 & & & & 0.43 & \\
\hline Q4_2 & & & & 0.84 & \\
\hline Q4_3 & & & & 0.53 & \\
\hline Q4_4 & & & & & 0.62 \\
\hline Q4_5 & & & & & 0.71 \\
\hline Q4_6 & & & 0.77 & & \\
\hline Q4_7 & & & 0.78 & & \\
\hline
\end{tabular}

CEEA-ACEG21; Paper 145

University of Prince Edward Island; June 21 - 23, 2021- 4 of 7 -

\begin{tabular}{|l|c|c|c|c|c|}
\hline \multirow{2}{*}{$\begin{array}{c}\text { Survey } \\
\text { Question }\end{array}$} & \multicolumn{5}{|c|}{ Factor } \\
\hline & F1 & F2 & F3 & F4 & F5 \\
\hline Q4_8 & & & 0.63 & & \\
\hline Q4_9a & & 0.85 & & & \\
\hline Q4_10 & & 0.41 & & & \\
\hline Q4_11 & 0.51 & & & & \\
\hline Q4_12a & & 0.62 & & & \\
\hline Q4_13 a & & 0.62 & & & \\
\hline Q4_15 & 0.42 & & & & \\
\hline Q4_16 & 0.48 & & & & $0.48^{*}$ \\
\hline Q4_17 & 0.58 & & & & \\
\hline Q4_18 & 0.61 & & & & \\
\hline Q4_20 & 0.66 & & & & \\
\hline $\begin{array}{l}\text { a indicates negatively worded items. The scale was } \\
\text { reversed for analysis of these items. }\end{array}$ \\
\hline $\begin{array}{l}\text { * indicates factor loadings that were not incorporated } \\
\text { into factor scales }\end{array}$ \\
\hline Rotation converged in 6 iterations. \\
\hline
\end{tabular}

This is a strong factor analysis result, with a meritorious sample size, nearly $50 \%$ of the total variance explained, and each variable at least $16 \%$ of its variance explained by the factor. The survey questions represented in each factor suggest that the intended factors from the Future Time Perspective model are in fact representative of the data and can be used for the remainder of the analysis. The reliability of these factors is shown in Table 4. Cronbach's Alpha increases with the number of items in the subscale, but even the subscale with only 2 items is above the 0.5 "early stage research" threshold and near the 0.7 commonly accepted threshold [13, p. 602, 25].

Table 4: Reliability value, Cronbach's Alpha, for extracted factors.

\begin{tabular}{|l|c|c|}
\hline Factor & $\begin{array}{l}\text { Number } \\
\text { of Items }\end{array}$ & $\begin{array}{l}\text { Cronbach's } \\
\text { Alpha }\end{array}$ \\
\hline $\begin{array}{l}\text { F4: Effects of Future } \\
\text { on Present }\end{array}$ & 3 & 0.69 \\
\hline $\begin{array}{l}\text { F5: Perceptions of the } \\
\text { Future }\end{array}$ & 2 & 0.67 \\
\hline $\begin{array}{l}\text { F3: Perceptions of } \\
\text { Engineering Future }\end{array}$ & 3 & 0.79 \\
\hline F2: Connectedness & 4 & 0.74 \\
\hline F1: Present Action & 6 & 0.79 \\
\hline
\end{tabular}




\section{DISCUSSION}

The pilot study was an invaluable step in the instrument development process because it resulted in $25 \%$ of the survey questions being directly improved and a further 50\% indirectly improved through the modification of section prompts. One of the most important issues the pilot study identified was low variability in responses due to biased question prompt phrasing. All pilot study respondents were completely unwilling to answer "disagree". This finding was confirmed in the think-aloud portion of the pilot study and was addressed through a major rephrasing of the question prompts. The data of the full study showed that rephrasing the question prompts resolved the bias and restored natural variability, since over one third of respondents answered somewhat disagree, disagree, or strongly disagree at least once when filling out that section of the survey. The pilot study provided important evidence to support the validity of the instrument before data collection began. Nevertheless, the instrument could be further refined based on the data gathered during the course of the full study.

\subsection{Improvements to Survey}

The low reliability of the subscales withing the Learning Orientation Model survey questions forced each of those question to be analyzed individually. This led to a limitation of the study, which was the larger number of statistical tests being completed and the corresponding elevation in false positive risk [29]. This limitation was managed with a robust results-verification process, decreasing the acceptable $\mathrm{p}$ value from $\mathrm{p}=.05$, to $\mathrm{p}=.01$ and increasing the acceptable effect size to $0.6[30,31]$. The Learning Orientation Model did provide a good structure for developing a comprehensive set of survey questions to explore student success, however the failure of the Learning Orientation Model as a reliable factor structure limits the intended utility of this portion of the survey for future researchers unless improvements are made. Potential improvements can be focused on rewording certain questions in the unreliable subscales. For example, one question asked about the importance of "choosing stimulating electives" to a student's success. Perhaps the reference to electives had students thinking about their non-engineering electives and the question should be reworded to refer to "choosing stimulating courses" or "choosing stimulating elective engineering courses".

Considering the survey overall, the length of the survey could be reduced to focus on a fewer number of areas. There were 35 participants who filled out some of the survey but dropped out part-way through, indicating that the survey could have gotten slightly more traction if it was shorter. However, an $87 \%$ completion rate for a 60 question survey is more than satisfactory.

\subsection{Moving forward}

The overall study could be moved forward by further improving the instrument through a confirmation study, expanding the reach to a larger population, and incorporating an interview component to the data collection.

Moving forward, confirming the validity of survey sections that were shown by this study to have strong internal consistency and a robust factor structure, such as the proposed modifications to the Future Time Perspectives [16], could be done by gathering more data with the instrument in a follow-up study and completing a confirmatory factor analysis to confirm the factor structure.

Reaching a larger population by expanding to other Canadian engineering programs would allow better justification for the wider generalizability of the results of this study. Further expansion to other countries, particularly European countries and the United States, could provide interesting contrast, as the literature suggests that European researchers and American researchers tended to define student success differently. European researchers tend towards more open-ended definitions, while American researchers tend to prioritize student retention as well as academic achievement and grades [3].

Adding an interview process would introduce further depth and richness into the data set over and above the open-ended response questions. This would allow for the opportunity to explore interesting findings such as the fact that students indicated that their personal happiness and positive contributions to society will be important ways in which they measure their success in a future career. An interview could be done to probe why these criteria are not more highly prioritized as a way that students measure their success in their present undergraduate programs, given they feel it will be so important in the future. Another example would be to explore how future employability is an important factor in how students perceive their success during their undergraduate program. An interview could probe how students view the quality and quantity of their future employment opportunities in the engineering field.

\subsection{Increasing the Response Rate}

A successful method of increasing the response rate of this survey was through giving a very short (2 -3 minute) talk at the beginning or end of a lecture and projecting a QR code link to the survey to the class. Reiterating why the study was being done (to benefit current and future engineering students) seemed to help engage students in the idea. Having a QR code allowed students to access the link conveniently and in-the-moment while the idea was still fresh in their mind. This study's easily and often ignored "request for participants" email could have been much improved by structuring it in such a way as to present the benefit to the current and future engineering students in the subject line or early in the email. 


\section{CONCLUSION}

This study explored undergraduate engineering students' interpretations of their success. The instrument that was used was tested and improved with a convergent parallel mixed methods pilot study. In the full study, the Learning Orientation model questions were not found to contain reliable subscales and each question was instead analyzed individually. The Future Time Perspectives questions were found to contain a well-supported and reliable factor structure. This suggests that the modifications made to the original Future Time Perspectives survey [16] for the purpose of this study were successful and could be used in future research.

\section{Acknowledgements}

This research involved data collected on human subjects. All procedures performed in this study were in accordance with the ethical standards of Queen's University per file number: 6027682. Thank you to all study participants and those who assisted in distributing the survey.

\section{References}

[1] T. T. York, C. Gibson, and S. Rankin, "Defining and Measuring Academic Success," Practical assessment, research \& evaluation, vol. 20, no. 5, pp. 1-20, 2015.

[2] O. Hannon, L. R. Smith, and G. Lã, "Success at University: The Student Perspective," in Success in Higher Education, L. Wood and Y. Breyer Eds. Singapore: Springer, 2017.

[3] M. S. Ullrich, "Exploring Engineering Students' Interpretations of Success," Master of Applied Science, Department of Mechanical and Materials Engineering, Queen's University, Kingston, ON, 2020.

[4] R. Arum and J. Roksa, Academically Adrift: Limited Learning on College Campuses. Chicago: University of Chicago Press, 2011.

[5] J. W. Young, "Adjusting the Cumulative GPA Using Item Response Theory," Journal of educational measurement, vol. 27, no. 2, pp. 175-186, 1990, doi: 10.1111/j.1745-3984.1990.tb00741.x.

[6] S. O'Shea and J. Delahunty, "Getting through the day and still having a smile on my face ! How do students define success in the university learning environment?," Higher education research and development, vol. 37, no. 5, pp. 1062-1075, 2018, doi: 10.1080/07294360.2018.1463973.

[7] G. D. Kuh, J. Kinzie, J. A. Buckley, B. K. Bridges, and J. C. Hayek, What Matters to Student Success: A Review of the Literature. Commissioned Report for the National Symposium on Postsecondary Student Success: Spearheading a Dialog on Student Success Washington, DC: National Postsecondary Educational Cooperative, 2006.

[8] A. M. Stelnicki, D. W. Nordstokke, and D. H. Saklofske, "Who Is the Successful University Student?
An Analysis of Personal Resources," Canadian Journal of Higher Education, vol. 45, no. 2, pp. 214-228, 2015.

[9] M. Ullrich and D. S. Strong, "How students define their success: a research study," presented at the 2020 Canadian Engineering Education Association (CEEAACEG20) Conference, Concordia and McGill Universities, 2020.

[10] V. L. Plano Clark and J. W. Creswell, Understanding Research: A Consumer's Guide, Second ed. Pearson, 2015.

[11] L. Oksenberg and G. Kalton, "New Strategies for Pretesting Survey Questions," Journal of Official Statistics, vol. 7, no. 3, pp. 349-365, 1991.

[12] D. Collins, "Pretesting survey instruments: An overview of cognitive methods," Quality of Life Research, vol. 12, no. 3, pp. 229-238, 2003, doi: 10.1023/A:1023254226592.

[13] A. Field, Discovering Statistics Using IBM SPSS Statistics, Fifth ed. University of Sussex: SAGE Publications Inc., 2018.

[14] A. Hofmeyer, B. Sheingold, and R. Taylor, "Do You Understand What I Mean? How Cognitive Interviewing Can Strengthen Valid, Reliable Study Instruments And Dissemination Products," Journal of International Education Research, vol. 11, no. 4, p. 261, 2015, doi: 10.19030/jier.v11i4.9460.

[15] L. Beaty, G. Gibbs, and A. Morgan, "Learning Orientations and Study Contracts," The Experience of Learning: Implications for teaching and studying in higher education, F. Marton, D. Hounsell, and N. Entwistle, Eds., 3rd (Internet) ed. Edinburgh: University of Edinburgh, Centre for Teaching, Learning and Assessment, 2005, pp. 72-86. [Online]. Available: https://www.ed.ac.uk/institute-academicdevelopment/learning-teaching/research/experienceof-learning

[16] J. Chasmar and K. M. Ehlert, "Cluster Analysis Methods and Future Time Perspective Groups of Second Year Engineering Students in a MajorRequired Course," presented at the American Society for Engineering Education, Salt Lake City, Utah, 2018.

[17] S. E. Tabachnick, R. B. Miller, and G. E. Relyea, "The Relationships Among Students' Future-Oriented Goals and Subgoals, Perceived Task Instrumentality, and Task-Oriented Self-Regulation Strategies in an Academic Environment," Journal of Educational Psychology, vol. 100, no. 3, pp. 629-642, 2008, doi: 10.1037/0022-0663.100.3.629.

[18] J. Chasmar and L. Benson, "Future Time Perspective and Self-Regulated Learning: Multiple Case Studies in Industrial Engineering," presented at the American Society for Engineering Education, New Orleans, June 26-29, 2016.

[19] J. Simons, M. Vansteenkiste, W. Lens, and M. Lacante, "Placing Motivation and Future Time Perspective Theory in a Temporal Perspective," Educational Psychology Review, vol. 16, no. 2, pp. 121-139, 2004, doi: 10.1023/B:EDPR.0000026609.94841.2f.

[20] S. Tabachnick, "The impact of future goals on students' proximal subgoals and on their perceptions of task instrumentality," Doctor of Philosophy, Graduate 
Faculty, University of Oklahoma, Norman, Oklahoma, 2005.

[21] J. C. Hilpert, J. Husman, G. S. Stump, W. Kim, W. T. Chung, and M. A. Duggan, "Examining students' future time perspective: Pathways to knowledge building1," Japanese Psychological Research, vol. 54, no. 3, pp. 229-240, 2012, doi: 10.1111/j.14685884.2012.00525.x.

[22] J. Chasmar, "Connections Between Future Time Perspectives and Self-Regulated Learning for MidYear Engineering Students: A Multiple Case Study," Doctor of Philosophy, Graduate School, Clemson University, Clemson, NC, 2017.

[23] M. S. Litwin, How to Measure Survey Reliability and Validity, Thousand Oaks, California, 1995. [Online]. Available: https://methods.sagepub.com/book/how-tomeasure-survey-reliability-and-validity. Accessed on: 2020/06/08.

[24] G. Camilli, "Ongoing issues in test fairness," Educational Research and Evaluation: FAIRNESS ISSUES IN EDUCATIONAL ASSESSMENT, vol. 19, no. 2-3, pp. 104-120, 2013, doi: 10.1080/13803611.2013.767602.

[25] J. C. Nunnally, Psychometric Theory. New York: McGraw-Hill, 1978.

[26] H. F. Kaiser and J. Rice, "Little jiffy, mark 4," Educational and Psychological Measurement, vol. 34, no. 1, pp. 111-117, 1974.

[27] J. P. Stevens, Applied multivariate statistics for the social sciences, 4th ed. Hillsdale, NJ: Erlbaum, 2002.

[28] E. Pedhazur and L. Schmelkin, Measurement, Design, and Analysis: An Integrated Approach. Hillsdale, NJ: Erlbaum, 1991.

[29] D. J. Benjamin et al., "Redefine statistical significance," Nature Human Behaviour, vol. 2, no. 1, pp. 6-10, 2018/01/01 2018, doi: 10.1038/s41562-0170189-z.

[30] D. Trafimow et al., "Manipulating the Alpha Level Cannot Cure Significance Testing," Frontiers in psychology, vol. 9, 2018, doi: 10.3389/fpsyg.2018.00699.

[31] H. Crane, "The Impact of P-hacking on "Redefine Statistical Significance"," Basic and Applied Social Psychology, vol. 40, no. 4, pp. 219-235, 2018/07/04 2018, doi: 10.1080/01973533.2018.1474111.

\section{Appendix}

Table 5: Future Time Perspective survey questions, grouped by factor (F\#). Factor names are shown in Table 4.

\begin{tabular}{|l|l|}
\hline \multicolumn{1}{|c|}{$\#$} & \multicolumn{1}{|c|}{ Survey Question } \\
\hline Q4_1 & $\begin{array}{l}\text { My goals for my future career have an } \\
\text { (F4) }\end{array}$ \\
\hline $\begin{array}{l}\text { impact on the things I do now } \\
\text { (F4) }\end{array}$ & $\begin{array}{l}\text { My future career determines what is } \\
\text { important in my courses }\end{array}$ \\
\hline
\end{tabular}

\begin{tabular}{|c|c|}
\hline \# & Survey Question \\
\hline $\begin{array}{l}\text { Q4_3 } \\
(\mathrm{F} 4)\end{array}$ & $\begin{array}{l}\text { My future career influences what I learn } \\
\text { from my courses }\end{array}$ \\
\hline $\begin{array}{l}\text { Q4_4 } \\
(\mathrm{F} 5)\end{array}$ & $\begin{array}{l}\text { I am sure of what I want to do when I } \\
\text { graduate }\end{array}$ \\
\hline $\begin{array}{l}\text { Q4_5 } \\
(\mathrm{F} 5)\end{array}$ & $\begin{array}{l}\text { I know what I want to be doing in my career } \\
\text { in } 5 \text { to } 10 \text { years }\end{array}$ \\
\hline $\begin{array}{l}\text { Q4_6 } \\
\text { (F3) }\end{array}$ & $\begin{array}{l}\text { I plan to pursue a professional engineering } \\
\text { career }\end{array}$ \\
\hline $\begin{array}{l}\text { Q4_7 } \\
\text { (F3) }\end{array}$ & $\begin{array}{l}\text { Engineering is the most rewarding future } \\
\text { career I can imagine for myself }\end{array}$ \\
\hline $\begin{array}{l}\mathrm{Q} 4 \_8 \\
\left(\mathrm{~F} 3 \_\right.\end{array}$ & $\begin{array}{l}\text { My interest in an engineering major } \\
\text { outweighs any disadvantages I can think of }\end{array}$ \\
\hline $\begin{array}{l}\text { Q4_9 } \\
\text { (F2) }\end{array}$ & I don't think much about my future \\
\hline $\begin{array}{l}\text { Q4_10 } \\
\text { (F2) }\end{array}$ & $\begin{array}{l}\text { I consciously reflect on what I want to do } \\
\text { after I graduate }\end{array}$ \\
\hline $\begin{array}{l}\text { Q4_12 } \\
\text { (F2) }\end{array}$ & I don't like to plan for the future \\
\hline $\begin{array}{l}\text { Q4_13 } \\
\text { (F2) }\end{array}$ & $\begin{array}{l}\text { One should not think too much about the } \\
\text { future }\end{array}$ \\
\hline $\begin{array}{l}\text { Q4_11 } \\
\text { (F1) }\end{array}$ & $\begin{array}{l}\text { I actively consider my long-term success in } \\
\text { my day-to-day decisions and choices }\end{array}$ \\
\hline $\begin{array}{l}\text { Q4_15 } \\
\text { (F1) }\end{array}$ & $\begin{array}{l}\text { One should be taking steps in the present to } \\
\text { help realize future goals }\end{array}$ \\
\hline $\begin{array}{l}\text { Q4_16 } \\
\text { (F1) }\end{array}$ & I am executing my long-term plan \\
\hline $\begin{array}{l}\text { Q4_17 } \\
(\mathrm{F} 1)\end{array}$ & $\begin{array}{l}\text { I make thoughtful decisions about how I } \\
\text { spend my time so I can maximize my future } \\
\text { success }\end{array}$ \\
\hline $\begin{array}{l}\text { Q4_18 } \\
\text { (F1) }\end{array}$ & $\begin{array}{l}\text { I invest my efforts strategically with my } \\
\text { long-term success in mind }\end{array}$ \\
\hline $\begin{array}{l}\text { Q4_20 } \\
(\mathrm{F} 1)\end{array}$ & $\begin{array}{l}\text { The day-to-day decisions I am currently } \\
\text { making will benefit my long-term success }\end{array}$ \\
\hline Q4_14* & $\begin{array}{l}\text { It is important to have goals for where one } \\
\text { wants to be in } 5 \text { to } 10 \text { years. }\end{array}$ \\
\hline Q4_19* & $\begin{array}{l}\text { The choices I make now are based more on } \\
\text { my short-term success than my success } 5 \text { to } \\
10 \text { years after graduation. }\end{array}$ \\
\hline \multicolumn{2}{|c|}{ * indicates items removed from the survey } \\
\hline
\end{tabular}

